Revista Destaques Acadêmicos, Lajeado, v. 8, n. 4, 2016. ISSN 2176-3070 DOI: http://dx.doi.org/10.22410/issn.2176-3070.v8i4a2016.1236 www.univates.br/revistas

\title{
ESTUDO COMPARATIVO DA OPERAÇÃO DE SERVIÇO DE TI EM EMPRESAS DO VALE DO TAQUARI/RS, COM BASE EM ITIL v3
}

\author{
Rafael Ferreira de Oliveira' ${ }^{1}$ Edson Moacir Ahlert ${ }^{2}$, Edson Funke $^{3}$
}

Resumo: Este artigo tem como objetivo analisar a maturidade, utilizando a metodologia PMF na etapa de Operação de Serviço de TI, de três empresas, situadas na região do Vale do Taquari/RS. Inicialmente, o trabalho apresenta uma visão geral da tecnologia da informação, definindo conceitos sobre Governança de TI e Gerenciamento de Serviços de TI, detalhamento da etapa da Operação de Serviço de TI e Maturidade de Processos, de acordo com as práticas da ITIL. A natureza da pesquisa é de caráter aplicada, a abordagem do problema é qualitativa, quanto aos objetivos é exploratória e quanto aos procedimentos técnicos é um estudo de caso. A pesquisa foi realizada por meio de um questionário semiestruturado, pelo qual revelou-se a maturidade da Operação de Serviço de TI, com base nas práticas ITIL v3.

Palavras-chave: Tecnologia da Informação. ITIL. Operação de Serviço.

\section{Introdução}

A visão da TI como arma estratégica é um fator crítico de sucesso para a organização, desde que exista um alinhamento das tecnologias aos negócios. Para isso, as empresas estão buscando iniciativas para a implantação da Governança de TI, que consiste em processos e práticas que garantam que o uso da TI agregue valor ao negócio da organização.

A Governança de TI é parte integrante da Governança Corporativa, ambas são fundamentais para o entendimento do papel da TI na organização. Segundo Oliveira (2006), a Governança Corporativa consiste de um conjunto de práticas administrativas, formais ou informais, consolidadas de acordo com a estrutura organizacional, ou seja, práticas consolidadas por questões

1 Bacharel em Administração de Empresas, Univates.

2 Mestre em Ambiente e Desenvolvimento, professor da Univates.

3 Mestre em Engenharia de Produção, professor da Univates. 
legais e formalmente estruturadas ou práticas voltadas para resultados, que não dependem da existência de estrutura organizacional para alcançar seus objetivos.

Para alcançar a integração da TI ao negócio, esta precisa adotar uma postura proativa para conseguir atender as necessidades da organização e gerar valor ao negócio. Para isso, é necessário gerenciar os serviços de TI para transformar habilidades e recursos em serviços de forma eficaz e eficiente. Em virtude desse cenário, onde a TI busca otimizar processos, reduzir custos e riscos, surgiram diversos frameworks e melhores práticas, bem-sucedidas, que preenchem espaços entre as necessidades dos clientes e a qualidade de serviço.

A metodologia de maior contribuição para o Gerenciamento de Serviços de TI é a ITIL (Information Technology Infrastructure Library), conjunto de melhores práticas orientada a serviços, com o propósito de gerenciar o seu ciclo de vida (FERNANDES; ABREU, 2012).

Este trabalho tem como objetivo identificar o grau de maturidade de três empresas do Vale do Taquari na etapa de Operação de Serviço de TI, perante as práticas da ITIL v3. O objetivo geral se desdobra nas seguintes questões específicas: A) descrever as práticas de ITIL; B) verificar processos e práticas desenvolvidas pelas empresas dentro da etapa da Operação do Serviço de TI; C) desenvolver e validar uma ferramenta de avaliação de maturidade para a etapa da Operação de Serviço de TI, com base em ITIL v3; D) sugerir ações de melhorias na etapa da Operação de Serviço de TI.

No cenário atual as organizações estão cada vez mais dependentes do gerenciamento de serviços de TI, pois o alinhamento estratégico entre a TI e o negócio é essencial para agregar valor aos clientes em forma de serviços. Dessa forma procura-se responder o seguinte problema de pesquisa: Qual o nível de maturidade das Empresas avaliadas na etapa de Operação do Serviço de TI, perante as práticas da ITIL?

\section{Governança corporativa e Governança de TI}

A governança corporativa surgiu na primeira metade dos anos 90 através de um movimento iniciado no Reino Unido, onde buscavam a transparência e integridade em relação às práticas de negócios. Com o passar do tempo, a Organização para a Cooperação e Desenvolvimento Econômico (OCDE), reforça a ideia da adoção de medidas para manter a base da boa governança, lançando um documento denominado Princípios da Governança Corporativa (SILVEIRA, 2015).

A Governança corporativa aplicada ao negócio proporciona mais agilidade, transparência e autonomia para as atividades e processos da empresa. Estas práticas podem ser absorvidas pelas diversas áreas da empresa, como, por exemplo, a TI, adaptando práticas à sua realidade. 
No decorrer dos anos, a tecnologia da informação tem sido essencial para as organizações, mas ao mesmo tempo preocupante. $\mathrm{O}$ uso intensivo das ferramentas de informação torna as organizações reféns da TI, consequentemente as exigências por disponibilidade de acesso às informações aumentam por ser um fator estratégico. Por conta dessa preocupação, e dentre outras, a Governança de TI ganha força com o estabelecimento de melhores práticas que visam o gerenciamento dos processos, e asseguram o alinhamento da TI com os objetivos da organização.

Mansur (2007) acredita que as necessidades da governança de TI tiveram início nos anos 90, quando questões relativas à qualidade de processos como controle, transparência e previsibilidade das organizações passaram ser um diferencial competitivo e começaram a ganhar mais atenção no cenário mundial. No mesmo período, a economia mundial teve forte crescimento e, mesmo com a alta demanda, a necessidade por governança passou a diminuir de intensidade. Na segunda metade dos anos 90 a governança volta à pauta nas organizações, logo após as crises na Ásia, México, Rússia, etc. quando obrigou as altas direções a uma reorganização orçamentária, visando maior precisão das informações financeiras e diminuição dos riscos de investimentos (MANSUR, 2007).

Por fim, é importante ressaltar que a Governança de TI permite que a TI desempenhe seu papel de forma transparente, alinhando seus propósitos aos requisitos do negócio.

\subsection{Gerenciamento de serviço de TI}

Para Magalhães e Pinheiro (2007, p. 29) conceituam o Gerenciamento de Serviços de TI como:

[...] o instrumento pelo qual a área pode iniciar a adoção de uma postura proativa em relação ao atendimento das necessidades da organização, contribuindo para evidenciar a sua participação na geração de valor. O Gerenciamento de Serviços de TI visa alocar adequadamente os recursos disponíveis e gerenciá-los de forma integrada, fazendo com que a qualidade do conjunto seja percebida pelos seus clientes e usuários, evitando-se a ocorrência de problemas na entrega e na operação dos serviços de Tecnologia da Informação.

Magalhães e Pinheiro (2007) destacam que o Gerenciamento de Serviço de TI é um elemento essencial para o alcance da maturidade e sua manutenção buscando a credibilidade para com a organização.

A ITIL é o modelo de gerenciamento de serviços de TI mais utilizado no cenário mundial, e preocupa-se em entregar e desenvolver os serviços com maior qualidade ao cliente com o foco no alinhamento estratégico ao negócio. Destaca também que os serviços de TI são abastecidos pelo gerenciamento de 
infraestrutura de TI, que inclui software, hardware, métodos, conhecimento e pessoas (MANSUR, 2007).

A ITIL v3 (Versão 3) possui um ciclo de vida de serviços dividido em cinco etapas dos serviços de TI que comprovam a estrutura, o equilíbrio e a resistência das habilidades de Gerenciamento de Serviço. São elas: Estratégia de Serviço, Desenho de Serviço, Transição de Serviço, Operação de Serviço e Melhoria Contínua de Serviço, conforme mostra a Figura 1, a seguir.

Figura 1 - Ciclo de vida da ITIL v3

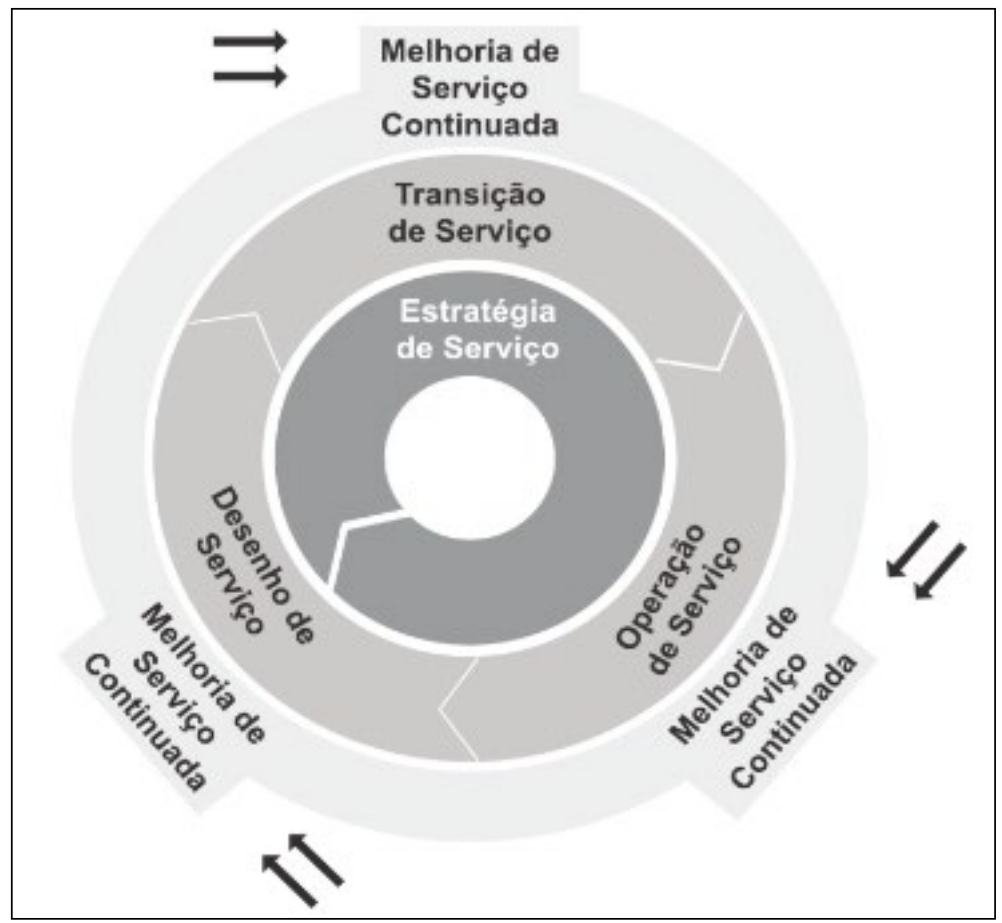

Fonte: Fernandes e Abreu (2008, p. 274).

A Estratégia do Serviço ajuda a compor o principal do ciclo de vida do serviço. Nela, o objetivo é fornecer os critérios que visam ajudar a desenvolver e implementar o gerenciamento de serviço como um ativo estratégico para a organização e possui três processos de gerenciamento de serviços: o Gerenciamento Financeiro de TI, o Gerenciamento de Portfólio de Serviços e o Gerenciamento de Demanda.

O Desenho do Serviço é a fase do ciclo de vida do serviço que prepara e gerencia o desenvolvimento de serviços e processos de gerenciamento de serviços que visam assegurar a qualidade da entrega, tanto para aumentar quanto para manter o valor aos clientes. Possui sete processos: Gerenciamento de Nível de Serviço, Gerenciamento de Catálogo de Serviço, Gerenciamento de 
Disponibilidade, Gerenciamento de Segurança da Informação, Gerenciamento de Fornecedor, Gerenciamento de Capacidade e Gerenciamento de Continuidade de Serviço de TI.

A Transição de serviço é uma importante etapa do ciclo de vida do serviço por arquitetar, avaliar e liberar para a próxima fase todos os serviços que foram estabelecidos nas etapas de Estratégia e Desenho do Serviço. Esta etapa possui quatro processos: Gerenciamento de Mudança, Gerenciamento de Configuração e Ativo de Serviço, Gerenciamento de Liberação e Gerenciamento de Conhecimento.

Cestari Filho (2011) assegura que a Operação de Serviços tem como objetivo garantir a realização dos processos e atividades de TI e gerenciar serviços, de modo que atendam aos níveis acordados com os clientes.

A Melhoria Contínua de Serviços (Continual Service Improvement) tem como propósito o alinhamento permanente dos serviços de TI para que as necessidades de negócios estejam em constante evolução, constatando e realizando melhorias nos serviços que apoiam todas as etapas do ciclo de vida do serviço. Os processos necessitam de otimização com vistas à eficiência, eficácia e rentabilidade (CASE; SPALDING, 2007).

A Melhoria Contínua de Serviço tem como intuito que as organizações percebam a qualificação dos serviços por meio de operações eficientes e atividades que geram valor para o negócio.

Sendo assim a ITIL não determina processos a serem seguidos pela TI, mas oferece melhores práticas que podem ser adaptadas conforme a execução dos processos de cada organização

\subsection{Operação de serviço de TI}

A Operação de Serviço é formado por cinco processos: Gerenciamento de Incidente, Gerenciamento de Evento, Cumprimento de Requisição, Gerenciamento de Problema e Gerenciamento de Acesso. Cada gerenciamento avalia processos e atividades específicas e contribui para que os objetivos da Operação sejam alcançados.

De acordo com Cannon e Wheeldon (2007), o Gerenciamento de Incidentes é o processo utilizado para tratar erros e incertezas apontados pelos usuários, sendo que a maior parte das ações desse processo são realizadas através de uma Central de serviços. Tem como objetivo restabelecer a operação de um serviço à sua normalidade, reduzir o impacto no negócio e assegurar a qualidade do serviço conforme estabelecido no SLA.

A ocorrência de um ou mais incidentes é definido pelo ITIL como um problema (CANNON; WHEELDON, 2007). Para analisar o impacto dos problemas e incidentes sobre o negócio é necessário associar os registros de incidentes aos de problemas para o efetivo Gerenciamento de Problemas. 
A relação entre os registros de problemas e incidentes permite que o Gerenciamento de Problema defina o impacto dos problemas sobre o negócio. Neste contexto, para a melhoria da execução do serviço de TI, a satisfação de seus usuários e a identificação de fragilidade em infraestrutura de TI, são necessárias medidas proativas com base na análise de relatórios de incidentes e problemas (MAGALHÃES; PINHEIRO, 2007).

Cannon e Wheeldon (2007) definem Gerenciamento de Acesso como uma autorização concedida a usuários para uso de determinado serviço, impedindo assim acessos indevidos e não autorizados de usuários. O Gerenciamento de Acesso também é conhecido em diversas organizações como Gestão de Identidade ou Gestão de Direitos.

O Gerenciamento de Acesso, aliado como a Segurança da Informação, possibilita que a organização gerencie o sigilo, a disponibilidade e a integridade de seus dados, bem como sua propriedade intelectual.

Qualquer ocorrência percebida que tenha valor para o gerenciamento de infraestrutura ou à entrega de serviços de TI e à análise do resultado de um desvio dos serviços pode ser denominada como evento. Eventos devem gerar notificações originadas por ferramentas de monitoramento, itens de configuração ou serviços de TI (CANNON; WHEELDON, 2007).

Cannon e Wheeldon (2007) destacam que o Gerenciamento de Eventos é a porta de entrada para a realização de vários outros processos e tarefas da Operação do Serviço e pode ser empregado a qualquer elemento que permita ser controlado e automatizado. Ele também proporciona a comparação do real desempenho e comportamento em relação ao desenho padrão do serviço e os acordos de nível do serviço (SLAs).

\subsection{Maturidade de processos}

As organizações colecionam processos, porém somente aquelas que buscam a melhoria contínua conseguem elevar seus níveis de desempenho. Para mensurar a capacidade de funcionamento das operações de TI é necessário gerar indicadores que, por sua vez, permitirão avaliar os níveis de maturidade da organização.

Marquis (2006, tradução livre) menciona que a maturidade está relacionada à capacidade de desempenho das organizações e sua avaliação se divide em níveis de maturidade, sendo que cada nível demonstra o desenvolvimento da capacidade dos processos organizacionais, quanto maior o grau de maturidade, mais otimizadas suas operações. Sendo assim, a maturidade indica quanto do ITIL é necessário implementar e por onde iniciar.

A disponibilidade de modelos de maturidade de processos é extensa, no entanto, dentre todos, o Process Maturity Framework (PMF - Modelo de Maturidade de Processos) é considerado o melhor desenvolvido para o ITIL (PEREIRA; SILVA apud SILVA, 2012). 
Sendo assim, ao analisar a maturidade por meio do PMF é possível verificar o nível de desempenho dos processos da organização, favorecendo a gestão do negócio e possibilitando uma visão sistêmica, fundamental para a implementação do ITIL.

\section{Método de avaliação da maturidade}

Nesta pesquisa serão utilizados documentos das empresas para compreensão e identificação das práticas da ITIL existentes, bem como para compor a caracterização de cada uma delas.

A população-alvo do estudo foi um funcionário do setor de tecnologia da informação, das três empresas participantes, localizadas na região do Vale do Taquari/RS. O levantamento das informações foi por meio de questionário semiestruturado durante o período de 21 de setembro a 9 de outubro.

O método do estudo foi baseado em um questionário elaborado por Lucinaldo Cirino da Silva (2012), o qual contém questões definidas para cada dimensão do ITIL e por processo conforme descrito no Modelo PMF, e também no Apêndice H do livro Service Design (COLIN; VERNON, 2007), que visam coletar informações precisas sobre cada processo.

As perguntas foram elaboradas com base nos cinco níveis de maturidade, do Modelo PMF, adotados para classificar a situação do processo e apontar a fase na qual se encontra a dimensão ITIL:

- Inicial (1);

- Repetitivo (2);

- Definido (3);

- Gerenciado (4);

- Otimizado (5).

O Nível Inicial (1), também é conhecido como "caótico" e significa que o processo é identificado mas existe pouca ou nenhuma atividade de gerenciamento e não são atribuídos importância, recursos ou foco dentro da organização (COLIN; VERNON, 2007, p. 393, tradução livre).

O segundo nível, nomeado como Repetitivo, indica que o processo é reconhecido, porém pouco valor, recursos ou foco são atribuídos dentro da operação. Geralmente as atividades são descoordenadas, irregulares, sem direção e estão orientadas para a efetividade do processo (COLIN; VERNON, 2007, p. 394, tradução livre).

Já o Nível Definido (3), demonstra que os processos são reconhecidos e estão documentados, porém não possuem acordos formais sobre seu papel dentro da operação de TI. O processo possui um responsável, metas e objetivos claros, disponibilização de recursos e é orientado para a eficiência e eficácia. 
Neste nível os relatórios e os resultados são armazenados para utilização futura (COLIN; VERNON, 2007, p. 395, tradução livre).

O processo classificado pelo Nível Gerenciado (4) representa total aceitação e reconhecimento pela operação de TI. Está focado nos serviços e seus objetivos e metas estão diretamente relacionados aos do negócio. $\mathrm{O}$ processo está estabelecido, gerenciado e tornou-se proativo, por meio de sua documentação e integração com outros processos de TI (COLIN; VERNON, 2007, p. 396, tradução livre).

Por fim, no Nível Otimizado (5), os processos são reconhecidos como um todo e possuem objetivos estratégicos e metas ajustadas aos objetivos gerais de negócios e de TI. As atividades estão institucionalizadas e são claras na visão dos envolvidos. Neste nível as ações são proativas e a melhoria contínua é parte do processo (COLIN; VERNON, 2007, p. 397, tradução livre).

A estruturação do questionário teve como base as dimensões do PMF dispostas no Apêndice H do Livro Service Design (COLIN; VERNON, 2007), sendo assim compõe 4 (quatro) gerenciamentos e o cumprimento de requisição, cada qual com 25 perguntas. As questões relativas a cada dimensão visam a identificação da maturidade das atividades realizadas nas empresas, classificando-as por nível, conforme o Quadro 9.

Ao responder o questionário de avaliação, o público-alvo indica uma pontuação estabelecida previamente (com valores $0,1,3$ e 5), a qual permite medir o nível de maturidade de cada processo, conforme mostra a Quadro 9.

A definição das notas pelo público-alvo fundamenta-se nos seguintes critérios de avaliação:

- Nota 0: Representa “Não" ou "Não existe", quanto aos processos ou atividades relacionadas à pergunta;

- Nota 1: Representa "Sim" ou “Existe(m)", quanto aos processos ou atividades relacionadas à pergunta, porém de forma incompleta, informal e reativa;

- Nota 3: Representa "Sim" ou "Existe(m)", quanto aos processos ou atividades relacionadas à pergunta, porém requer aperfeiçoamentos;

- Nota 5: Representa "Sim" ou "Existe(m)", quanto aos processos ou atividades relacionadas à pergunta, sendo classificado como satisfatório e dentro do padrão esperado (processo proativo).

Dadas as atribuições de nota para cada dimensão PMF, é realizada a média aritmética para alcançar o cálculo da maturidade das dimensões PMF. O benefício da utilização do modelo PMF para alcançar a análise de maturidade dos processos ITIL está na possibilidade de medir detalhadamente os processos de cada dimensão, a fim de observar e propor possíveis melhorias para as atividades abrangidas pelas dimensões. 
Ao definir a maturidade das dimensões, pode-se dizer que automaticamente se obtém a maturidade do processo. Contudo, cada dimensão do PMF tem seu proporcional grau de importância, sendo que é possível estipular prioridades na realização de atividades mediante propostas de melhoria com vistas a adicionar valor à gestão de serviços de TI. Dessa forma, Silva (2012) define ponderações, variando de 1 a 3, para determinar a importância de cada dimensão PMF.

O Quadro 1 é a representação de todos os passos mencionados anteriormente, com as oportunas notas, indicação da maturidade da dimensão PMF e processo, assim como exemplifica o questionário proposto neste estudo.

Quadro 1 - Modelo de questionário de avaliação de maturidade

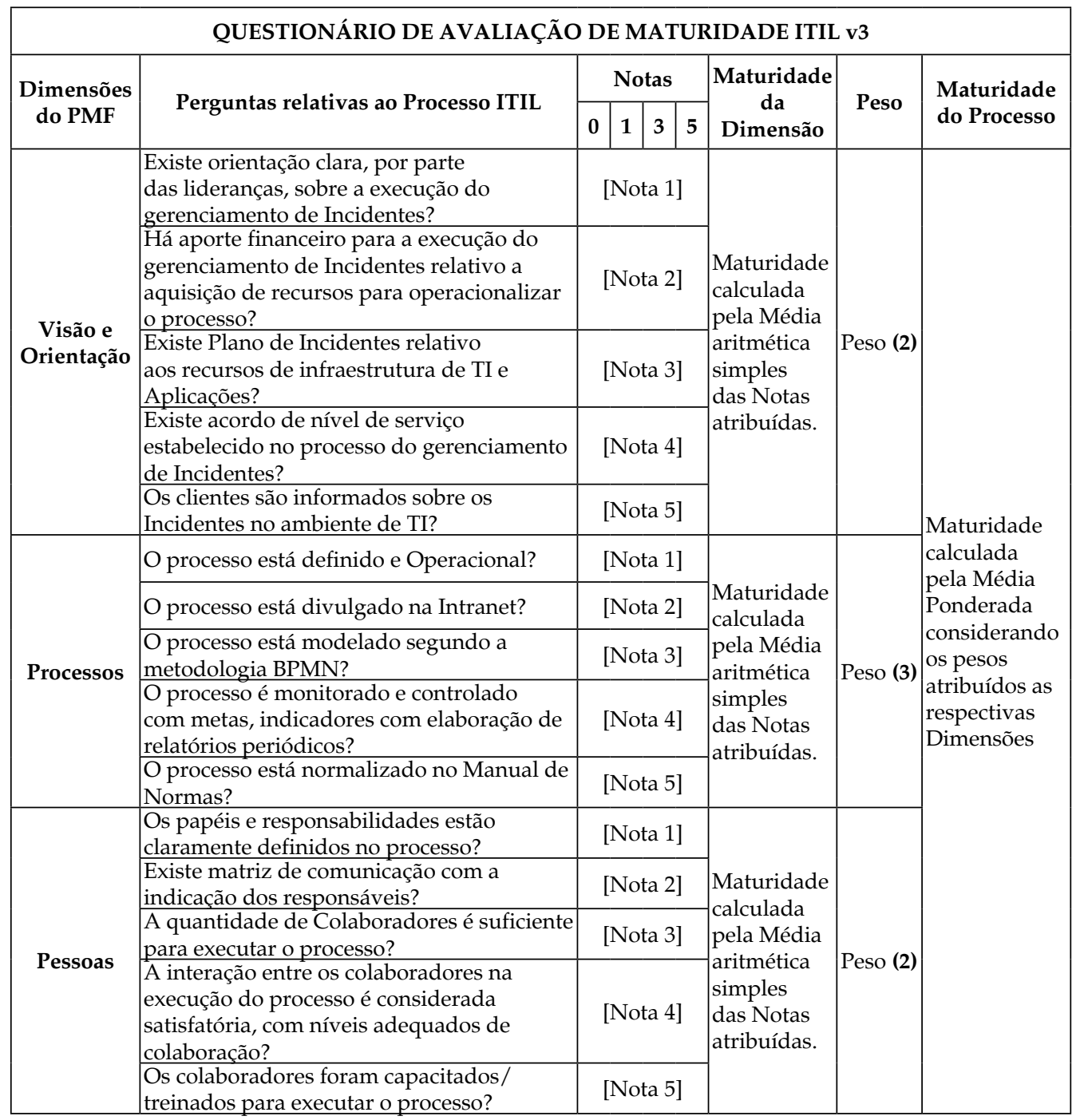




\begin{tabular}{|c|c|c|c|c|c|c|c|}
\hline \multicolumn{8}{|c|}{ QUESTIONÁRIO DE AVALIAÇÃO DE MATURIDADE ITIL v3 } \\
\hline \multirow{2}{*}{$\begin{array}{l}\text { Dimensões } \\
\text { do PMF }\end{array}$} & \multirow{2}{*}{ Perguntas relativas ao Processo ITIL } & \multicolumn{3}{|c|}{ Notas } & \multirow{2}{*}{$\begin{array}{l}\text { Maturidade } \\
\text { da } \\
\text { Dimensão }\end{array}$} & \multirow{2}{*}{ Peso } & \multirow{2}{*}{$\begin{array}{l}\text { Maturidade } \\
\text { do Processo }\end{array}$} \\
\hline & & 0 & 1 & $3 \mid 5$ & & & \\
\hline \multirow{5}{*}{ Tecnologia } & $\begin{array}{l}\text { Existe(m) ferramenta(s) que automatiza o } \\
\text { processo? }\end{array}$ & \multicolumn{3}{|c|}{ [Nota 1] } & \multirow{5}{*}{$\begin{array}{l}\text { Maturidade } \\
\text { calculada } \\
\text { pela Média } \\
\text { aritmética } \\
\text { simples } \\
\text { das Notas } \\
\text { atribuídas. }\end{array}$} & \multirow{5}{*}{ Peso (2) } & \multirow{5}{*}{$\begin{array}{l}\text { Maturidade } \\
\text { calculada } \\
\text { pela Média } \\
\text { Ponderada } \\
\text { considerando } \\
\text { os pesos } \\
\text { atribuídos as } \\
\text { respectivas } \\
\text { Dimensões }\end{array}$} \\
\hline & $\begin{array}{l}\text { Existe integração entre as ferramentas que } \\
\text { automatizam outros processos? }\end{array}$ & \multicolumn{3}{|c|}{ [Nota 2] } & & & \\
\hline & $\begin{array}{l}\text { Existe base de dados onde são } \\
\text { armazenados os dados do processo? }\end{array}$ & \multicolumn{3}{|c|}{ [Nota 3] } & & & \\
\hline & $\begin{array}{l}\text { O suporte técnico da(s) ferramenta(s) está } \\
\text { adequado? }\end{array}$ & \multicolumn{3}{|c|}{$[$ Nota 4$]$} & & & \\
\hline & São gerados relatórios automáticos? & \multicolumn{3}{|c|}{ [Nota 5] } & & & \\
\hline \multirow{5}{*}{ Cultura } & $\begin{array}{l}\text { Existe a compreensão clara que o } \\
\text { gerenciamento dos processos melhora } \\
\text { desempenho da TI? }\end{array}$ & & {$[\mathrm{Not}$} & a 1] & \multirow{5}{*}{$\begin{array}{l}\text { Maturidade } \\
\text { calculada } \\
\text { pela Média } \\
\text { aritmética } \\
\text { simples } \\
\text { das Notas } \\
\text { atribuídas. }\end{array}$} & \multirow{5}{*}{ Peso (1) } & \\
\hline & $\begin{array}{l}\text { Os Colaboradores que executam o processo } \\
\text { sabem da sua importância para o negócio } \\
\text { da empresa? }\end{array}$ & & {$[$ Not } & a 2] & & & \\
\hline & $\begin{array}{l}\text { Existe de forma satisfatória a disseminação } \\
\text { / compartilhamento das informações sobre } \\
\text { os processos de TI? }\end{array}$ & & {$[\mathrm{Not}$} & a 3] & & & \\
\hline & $\begin{array}{l}\text { Existe um canal para que os colaboradores } \\
\text { possam sugerir melhorias ao processo? }\end{array}$ & \multicolumn{3}{|c|}{ [Nota 4] } & & & \\
\hline & $\begin{array}{l}\text { A publicidade/divulgação do processo está } \\
\text { adequada e satisfatória? }\end{array}$ & \multicolumn{3}{|c|}{ [Nota 5] } & & & \\
\hline
\end{tabular}

Fonte: Adaptado pelo autor com base em Silva (2012, p. 40-41).

A partir das informações estabelecidas pelo público-alvo é realizado o cálculo da maturidade de cada dimensão por meio da média aritmética da composição de notas. As dimensões recebem pesos, sendo que estes serão utilizados para um cálculo de média ponderada, o qual fornecerá o resultado numérico do nível de maturidade, variável entre zero e cinco. Cada resultado é classificado em determinadas faixas de valores, permitindo a identificação da maturidade, conforme exibido na Figura 2.

Figura 2 - Níveis de maturidade do processo

\begin{tabular}{|l|c|c|}
\hline \multicolumn{1}{|c|}{ Valor da Maturidade } & \multicolumn{2}{c|}{ Niveis } \\
\hline Menor igual a 1,9 & $\mathbf{1}$ & Inicial \\
\hline Maior igual a 2 e menor igual a 2,9 & $\mathbf{2}$ & Repetitivo \\
\hline Maior igual a 3 e menor igual a 3,9 & $\mathbf{3}$ & Definido \\
\hline Maior igual a 4 e menor igual a 4,9 & $\mathbf{4}$ & Gerenciado \\
\hline Igual a 5 & $\mathbf{5}$ & Otimizado \\
\hline \hline
\end{tabular}

Fonte: Silva (2012, p. 41). 
Definidos os níveis de maturidade da dimensão e dos processos, são facilitados o planejamento e determinação de melhorias, por meio da visão sistêmica, bem como da análise individual de cada processo.

\subsection{Modelo matemático e sua aplicação}

A Média Aritmética Simples é utilizada para realização do cálculo matemático da maturidade das dimensões de cada processo, conforme segue.

$$
\begin{gathered}
\text { Maturidade }_{\text {Dimensio }}=\frac{\text { Nota } 1+\text { Nota } 2+\text { Nota } 3+\text { Nota } 4+\text { Nota } 5}{5} \\
=\frac{\sum_{\mathrm{i}=1}^{5}\left(\text { Nota }_{i}\right)_{\text {Dimensão }}}{5}
\end{gathered}
$$

Os resultados obtidos do cálculo citado anteriormente, bem como os pesos predeterminados para cada dimensão (Visão/Orientação: peso 2; Processos: peso 3; Pessoas: peso 2; Tecnologia: peso 2 e Cultura: peso 1) serão aplicados ao cálculo da Média Ponderada para obtenção da maturidade dos processos:

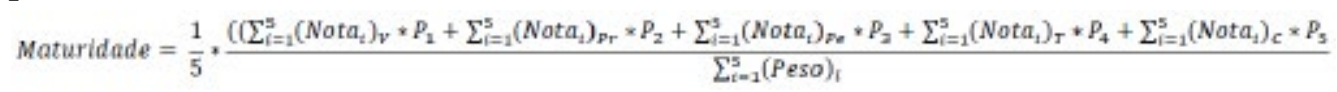

Dessa forma, considerando a somatória dos pesos $\sum_{t=1}^{5}(\text { Peso })_{l}=2+3+2+2+1=10$, é possível obter o cálculo geral da maturidade de processos conforme cálculo anterior.

Tendo o modelo matemático definido, as fórmulas anteriormente relacionadas são aplicadas à planilha eletrônica MS Excel a fim de obter resultados imediatos do cálculo de maturidade ao tempo que o público-alvo realizar o preenchimento dos dados das notas. A Figura 9 mostra o modelo da planilha eletrônica mencionado.

A coloração apresentada nos resultados corresponde ao nível de maturidade dos processos encontrado, tem propósito instrutivo e objetiva facilitar a análise e simplificar sua interpretação para realçar o resultado.

Dito isso, os resultados gerados pela planilha eletrônica MS Excel possibilitam ao avaliador identificar automaticamente o nível da maturidade de forma ágil e eficaz, possibilitando melhor gerenciamento e qualificação dos processos.

\section{Apresentação e análise dos resultados da empresa $\mathrm{A}$}

Este capítulo apresenta e analisa os dados coletados por meio de questionário semiestruturado aplicado em três empresas, aqui denominadas de $\mathrm{A}, \mathrm{B}$ e $\mathrm{C}$, em relação à maturidade dos processos pertencentes a etapa da Operação do Serviço do ITIL v3, tendo em vista os objetivos estabelecidos neste 
estudo. Sendo assim, são apresentados e analisados os dados com base nos resultados obtidos através da aplicação do questionário.

Para demonstração da aplicação do método, será feita a análise apenas da empresa A, visto que para as outras duas os procedimentos apenas se repetiriam. O objetivo aqui é comprovar a aplicação do questionário e da ferramenta para avaliação da maturidade.

Com base no resultado do questionário, onde cada gerenciamento foi avaliado separadamente, foi possível classificar os processos ITIL, executados pela empresa A em seu atual estágio, nos níveis de maturidade estabelecidos no modelo PMF, bem como diagnosticar pontos fortes e fracos nas dimensões avaliadas e sugestão de melhorias. Neste estudo é apresentado somente o resultado obtido no Gerenciamento de Incidentes, o processo de avaliação se repete para os demais gerenciamentos da etapa da Operação do Serviço.

Quanto ao tema Gerenciamento de Incidentes, a Empresa A respondeu ao questionário conforme mostra o Quadro 2.

Quadro 2 - Questionário do Gerenciamento de Incidentes - Empresa A

\begin{tabular}{|c|c|c|c|c|c|}
\hline \multicolumn{6}{|c|}{ AVALIAÇÃO DE MATURIDADE ITIL v3 - OPERAÇÃO DO SERVIÇO } \\
\hline \multicolumn{6}{|c|}{ Questionário para Gerenciamento de Incidentes } \\
\hline \multirow{2}{*}{$\begin{array}{l}\text { Dimensões da } \\
\text { Maturidade } \\
\text { dos Processos }\end{array}$} & \multirow[t]{2}{*}{ Perguntas relativas ao Processo ITIL } & \multicolumn{4}{|c|}{$\begin{array}{c}\text { Questionários } \\
\text { e respectivas } \\
\text { notas }\end{array}$} \\
\hline & & 0 & 1 & 3 & 5 \\
\hline \multirow{5}{*}{$\begin{array}{l}\text { Visão e } \\
\text { Orientação }\end{array}$} & $\begin{array}{l}\text { Existe orientação clara, por parte das lideranças, sobre a execução do } \\
\text { gerenciamento de Incidentes? }\end{array}$ & \multicolumn{4}{|c|}{1} \\
\hline & $\begin{array}{l}\text { Há aporte financeiro para a execução do gerenciamento de Incidentes } \\
\text { relativo a aquisição de recursos para operacionalizar o processo? }\end{array}$ & \multicolumn{4}{|c|}{1} \\
\hline & $\begin{array}{l}\text { Existe Plano de Incidentes relativo aos recursos de infraestrutura de TI e } \\
\text { Aplicações? }\end{array}$ & \multicolumn{4}{|c|}{0} \\
\hline & $\begin{array}{l}\text { Existe acordo de nível de serviço estabelecido no processo do } \\
\text { gerenciamento de Incidentes? }\end{array}$ & \multicolumn{4}{|c|}{3} \\
\hline & Os clientes são informados sobre os Incidentes no ambiente de TI? & \multicolumn{4}{|c|}{1} \\
\hline \multirow{5}{*}{ Processos } & O processo está definido e Operacional? & \multicolumn{4}{|c|}{3} \\
\hline & O processo está divulgado na Intranet? & \multicolumn{4}{|c|}{1} \\
\hline & O processo está modelado segundo a metodologia BPMN? & \multicolumn{4}{|c|}{1} \\
\hline & $\begin{array}{l}\text { O processo é monitorado e controlado com metas, indicadores com } \\
\text { elaboração de relatórios periódicos? }\end{array}$ & \multicolumn{4}{|c|}{1} \\
\hline & O processo está normalizado no Manual de Normas? & \multicolumn{4}{|c|}{0} \\
\hline
\end{tabular}




\begin{tabular}{|c|c|c|c|c|c|}
\hline \multicolumn{6}{|c|}{ AVALIAÇÃO DE MATURIDADE ITIL v3 - OPERAÇÃO DO SERVIÇO } \\
\hline \multicolumn{6}{|c|}{ Questionário para Gerenciamento de Incidentes } \\
\hline \multirow{2}{*}{$\begin{array}{c}\text { Dimensões da } \\
\text { Maturidade } \\
\text { dos Processos }\end{array}$} & \multirow[t]{2}{*}{ Perguntas relativas ao Processo ITIL } & \multicolumn{4}{|c|}{$\begin{array}{c}\text { Questionários } \\
\text { e respectivas } \\
\text { notas }\end{array}$} \\
\hline & & 0 & 1 & 3 & 5 \\
\hline \multirow{5}{*}{ Pessoas } & Os papéis e responsabilidades estão claramente definidos no processo? & \multicolumn{4}{|c|}{3} \\
\hline & Existe matriz de comunicação com a indicação dos responsáveis? & \multicolumn{4}{|c|}{1} \\
\hline & A quantidade de Colaboradores é suficiente para executar o processo? & \multicolumn{4}{|c|}{3} \\
\hline & $\begin{array}{l}\text { A interação entre os colaboradores na execução do processo é considerada } \\
\text { satisfatória, com níveis adequados de colaboração? }\end{array}$ & \multicolumn{4}{|c|}{3} \\
\hline & Os colaboradores foram capacitados/treinados para executar o processo? & \multicolumn{4}{|c|}{3} \\
\hline \multirow{5}{*}{ Tecnologia } & Existe $(\mathrm{m})$ ferramenta (s) que automatiza o processo? & \multicolumn{4}{|c|}{3} \\
\hline & Existe integração entre as ferramentas que automatizam outros processos? & \multicolumn{4}{|c|}{1} \\
\hline & Existe base de dados onde são armazenados os dados do processo? & \multicolumn{4}{|c|}{3} \\
\hline & O suporte técnico da (s) ferramenta (s) está adequado? & \multicolumn{4}{|c|}{3} \\
\hline & São gerados relatórios automáticos? & \multicolumn{4}{|c|}{3} \\
\hline \multirow{5}{*}{ Cultura } & $\begin{array}{l}\text { Existe a compreensão clara que o gerenciamento dos processos melhora } \\
\text { desempenho da TI? }\end{array}$ & \multicolumn{4}{|c|}{3} \\
\hline & $\begin{array}{l}\text { Os Colaboradores que executam o processo sabem da sua importância para } \\
\text { o negócio da empresa? }\end{array}$ & \multicolumn{4}{|c|}{3} \\
\hline & $\begin{array}{l}\text { Existe de forma satisfatória a disseminação/compartilhamento das } \\
\text { informações sobre os processos de TI? }\end{array}$ & \multicolumn{4}{|c|}{3} \\
\hline & $\begin{array}{l}\text { Existe um canal para que os colaboradores possam sugerir melhorias ao } \\
\text { processo? }\end{array}$ & \multicolumn{4}{|c|}{3} \\
\hline & A publicidade/divulgação do processo está adequada e satisfatória? & \multicolumn{4}{|c|}{1} \\
\hline
\end{tabular}

Fonte: Do autor, adaptado de Silva (2012).

Dados as notas para cada questão abrangida pelo Gerenciamento de Incidentes, pode-se verificar os pontos fracos e fortes da Empresa A. Na dimensão de Visão e Orientação, o processo mais crítico está na inexistência de um plano de incidentes relacionado aos recursos de Aplicações e infraestrutura de TI, seguido da informalidade na orientação sobre a execução do Gerenciamento de Incidentes por parte das lideranças, bem como a realização, de forma reativa, do aporte financeiro para a execução do gerenciamento de Incidentes relativo a aquisição de recursos para operacionalizar o processo e, também, a deficiência na informação sobre Incidentes aos clientes. Em contrapartida, o acordo de nível de serviço estabelecido no processo do gerenciamento de Incidentes está definido, tem visibilidade dentro da organização, porém necessita melhorias pontuais para os temas em questão.

Quanto à dimensão de Processos, não existem orientações, processos ou atividades relacionadas ao Manual de Normas. Outros pontos críticos estão na limitação da divulgação dos processos referentes a incidentes na Intranet, na 
modelação incompleta dos processos de incidentes segundo a Modelagem de Processos de Negócio (BPMN - Business Process Modeling Notation, em Português: Notação de Modelagem de Processos de Negócio, é uma ferramenta de apoio à modelagem de processos) e na informalidade de controle e monitoramento de metas, indicadores e elaboração de relatórios periódicos. Por outro lado, o processo de Incidentes é reconhecido, mas necessita desenvolvimento.

A dimensão Pessoas apresenta apenas um ponto que é reconhecido, mas não está claro, que diz respeito à matriz de comunicação com indicação dos responsáveis. Os demais processos avaliados na dimensão estão definidos e reconhecidos dentro da organização, porém todos apresentam pontos a melhorar.

Outra dimensão que apresenta mais pontos fortes que fracos é a de Tecnologia. Em relação a automatização de processos por meio da integração de ferramentas, o processo existe, porém de forma parcial. Os outros processos de incidentes analisados são reconhecidos e necessitam aprimoramento.

A dimensão Cultura não foge do padrão anterior, o processo que carece mais de atenção se refere à publicidade e divulgação, que existe, mas é realizado de maneira reativa. Os processos restantes estão instituídos e demandam pontos a melhorar.

A partir das respostas apresentadas obteve-se o valor de 1,9 pontos, classificando a maturidade do Gerenciamento de Incidentes em Nível Inicial (1), como mostra a Figura 3. 
Figura 3 - Maturidade do Gerenciamento de Incidentes - Empresa A

\begin{tabular}{|c|c|c|c|c|}
\hline EMPRESA & \multicolumn{4}{|c|}{ EMPRESAA } \\
\hline PROCESSO & Incidente & & & Escolha o processo a ser exibido \\
\hline $\begin{array}{c}\text { Dimensões do } \\
\text { Processo }\end{array}$ & Pesos & $\begin{array}{l}\text { Maturidade da } \\
\text { Dimensão }\end{array}$ & $\begin{array}{l}\text { Maturidade do } \\
\text { Processo ITIL }\end{array}$ & Nível da Maturidade do Processo \\
\hline Visão e Orientação & 2 & 1,2 & \multirow{5}{*}{1,9} & Nível Inicial (1) \\
\hline Processos & 3 & 1,2 & & \multirow{4}{*}{$\begin{array}{l}\text { O processo é reconhecido, porém existe pouca ou } \\
\text { nenhuma atividade na gestão dos processos, } \\
\text { tampouco é atribuído recurso, importância e foco às } \\
\text { atividades. Este nível também pode ser descrito como } \\
\text { "caótico". }\end{array}$} \\
\hline Pessoas & 2 & 2,6 & & \\
\hline Tecnologia & 2 & 2,6 & & \\
\hline Cultura & 1 & 2,6 & & \\
\hline
\end{tabular}

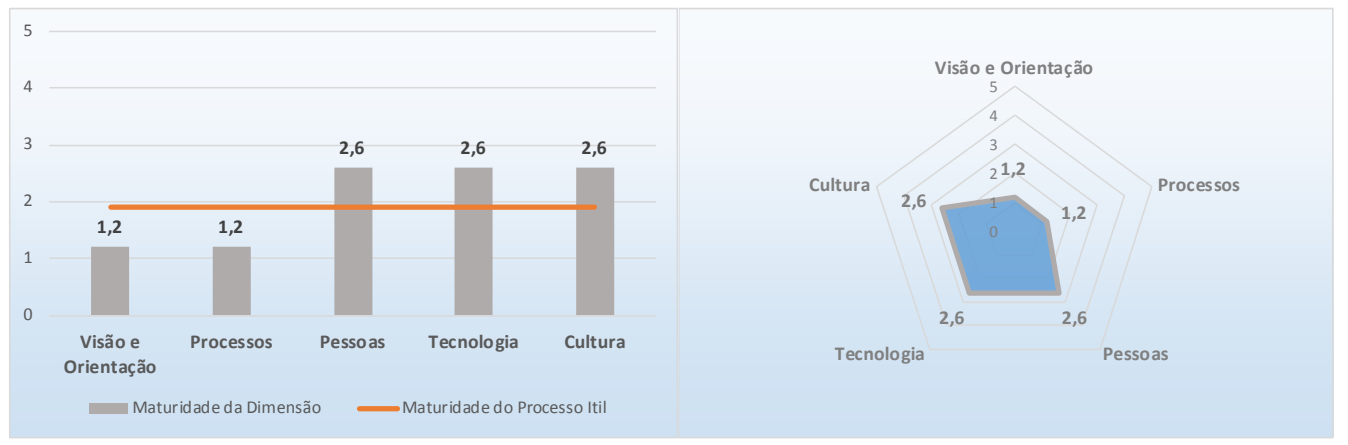

Fonte: Do autor, adaptado de Silva (2012).

O processo foi classificado no Nível Inicial (1) o que revela que é um processo reconhecido, porém é informal na sua maioria e não desperta a atenção dos gestores. Tendo em vista que o processo de Gerenciamento de Incidentes preocupa-se em sustentar a disponibilidade e confiabilidade dos serviços de TI, o nível atingido reflete uma situação de alerta que compromete a satisfação do cliente em relação à qualidade dos serviços de TI.

Os resultados podem ser melhor visualizados por meio dos gráficos junto a Figura 3, demonstrados a seguir. O primeiro gráfico, mostrado em formato "radar", que possibilita a visualização de forma abrangente e facilita a comparação dos dados evolutivos dos resultados de cada dimensão PMF.

O segundo gráfico relaciona os resultados obtidos nas dimensões PMF com a média ponderada obtida na maturidade do Gerenciamento de Incidentes. Esta comparação permite visualizar a distância das dimensões em relação à média. Sendo assim, pode-se visualizar que as dimensões Visão e Orientação e Processos tem resultados abaixo e, as dimensões Pessoas, Tecnologia e Cultura, acima da média. Como um todo as atividades relacionadas ao Gerenciamento de Incidentes são consideradas escassas no contexto no negócio. 
A partir das análises realizadas, pode-se sugerir as seguintes melhorias de processos:

- Manter as lideranças informadas quanto a execução dos processos de Gerenciamento de Incidentes;

- Aumentar o investimento na operacionalização do processo;

- Elaborar Plano de Incidentes ligado ao alinhamento entre o negócio e a TI;

- Disponibilizar informações sobre o gerenciamento de incidentes concentradas no acordo de nível de serviço;

- Publicar e comunicar onde está divulgado o processo;

- Realizar mapeamento e modelagem do processo com metodologia BPMN;

- Criar métricas e Keys Performance Indicator (KPIs), Indicador Chave de Performance, para controle de metas do processo;

- Criar matriz RACI - Responsável, Autoridade, Consultado e Informado (Ferramenta que auxilia na definição de responsabilidades de projetos e serviços específicos);

- Elaborar manual de normas a fim de orientar o processo de forma padronizada.

As indicações de melhorias foram baseadas e adaptadas de Colin e Vernon (2007).

\section{Considerações finais}

Em virtude do cenário, em que a Tecnologia da Informação busca agregar valor ao negócio, otimizando processos e reduzindo custos e riscos, surge a necessidade de diminuir a distância entre a expectativa do cliente e a qualidade real de entrega do serviço. Para preencher esta lacuna, são utilizadas metodologias, como a ITIL, para obter melhores práticas orientadas a serviços, com o propósito de gerenciar o seu ciclo de vida.

Neste contexto, o estudo procurou identificar o grau de maturidade de Operação de Serviço de TI, baseado nas práticas da ITIL v3, de três empresas da região do Vale do Taquari, por meio de pesquisa aplicada e qualitativa.

A ferramenta de avaliação foi elaborada com o intuito de aplicação nas empresas deste estudo, mas também para futura utilização, tanto de forma auto avaliativa, quanto por terceiros. Neste estudo ela foi aplicada a três empresas, porém comporta aplicação a um público-alvo em maior número e de diferentes áreas de atuação, não apenas a empresas do ramo de TI.

A ferramenta permitiu avaliar atual nível de maturidade dos processos por meio de classificação instantânea, à medida que questionário é preenchido por completo. A efetividade da ferramenta de avaliação é comprovada a partir 
do momento em que ela apresenta o nível de maturidade do estado atual do processo e se confirma pelo fato da sua aplicação ter se mostrado satisfatória.

A partir dos resultados obtidos, foi possível verificar as práticas desenvolvidas pela organização dentro da etapa de Operação de Serviço e, foi possível concluir que a Empresa A trabalha melhor os processos e atividades relacionados ao Gerenciamento de Problema e os que menos recebem atenção são os englobados no Cumprimento de Requisição. Em uma visão geral da maturidade do processo ITIL, as práticas e processos não são trabalhados ou desenvolvidos de forma satisfatória, por este motivo, foram sugeridas melhorias, atingindo um dos objetivos propostos neste trabalho.

Outro ponto que ainda merece destaque foi a oportunidade de observar quais são os processos críticos e que demandam atenção, o que possibilitou obter um panorama geral de cada gerenciamento para realização de um plano de ação para melhorias.

\section{REFERÊNCIAS}

CANNON, David; WHEELDON, David. Service Operation, ITIL, Version 3: Editora The Stationery Office, 2007. E-book. Disponível em:<http:/ /pc-freak.net/files/ITIL_ v3_books/>. Acesso em: 10 set. 2016.

CASE, Gary; SPALDING, George. Service Improvement, ITIL, Version 3: Editora The Stationery Office, 2007. E-book. Disponível em: $<$ http:/ /pc-freak.net/files/ITIL_v3_ books/>. Acesso em: 10 set. 2016.

CESTARI FILHO, Felício. ITIL v3 Fundamentos. Rio de Janeiro: RNP/ESR, 2011.

CHEMIM, Beatriz Francisca. Manual da Univates para trabalhos acadêmicos: planejamento, elaboração e apresentação. 2. ed. Lajeado: Univates, 2012.

COLIN Rudd, VERNON Lloyd. Service Design, ITIL, Version 3: Editora The Stationery Office, 2007. E-book. Disponível em: $<$ http:/ /pc-freak.net/files/ITIL_v3_ books/>. Acesso em: 10 set. 2016.

FERNANDES, Aguinaldo Aragon; ABREU, Vladimir Ferraz de. Implantando a governança de TI: da estratégia à gestão dos processos e serviços. 2. ed. Rio de Janeiro: Brasport, 2008. E-book. Disponível em: $<$ https://books.google.com.br/books?i $\mathrm{d}=\mathrm{IvLVUdfv} 158 \mathrm{C} \& \mathrm{lpg}=\mathrm{PP} 1 \& \mathrm{hl}=\mathrm{pt}-\mathrm{BR} \& \mathrm{pg}=\mathrm{PP} 1 \# \mathrm{v}=$ onepage $\& \mathrm{q} \& \mathrm{f}=$ false $>$. Acesso em: 02 set. 2016.

Implantando a governança de TI: da estratégia à gestão dos processos e serviços. 3. ed. Rio de Janeiro: Brasport, 2012.

GIL, Antônio Carlos. Métodos e técnicas de pesquisa social. 6. ed. São Paulo: Atlas, 2012. 
IQBAL Majid, NIEVES Michael. Service Strategy, ITIL, Version 3: Editora The Stationery Office, 2007. E-book. Disponível em:<http:/ / pc-freak.net/files/ITIL_v3_ books/>.Acesso em: 10 set. 2016.

ITpreneurs; AXELOS. ITIL Foundation. Porto Alegre, 2014. (Apostila do Curso de ITIL Foundation - Target Trust).

LACY, Shirley; MACFARLANE, Ivor. Service Transition, ITIL, Version 3: Editora The Stationery Office, 2007. E-book. Disponível em:<http:/ / pc-freak.net/files/ITIL_v3_ books/>. Acesso em: 10 set. 2016.

LAKATOS, Eva Maria; MARCONI, Marina de Andrade. Fundamentos de metodologia científica. 7. ed. São Paulo: Atlas, 2010.

MAGALHÃES, Ivan Luizio; PINHEIRO, Walfrido Brito. Gerenciamento de serviços de TI na prática: uma abordagem com base na ITIL: inclui ISO/IEC 20.000 e IT Flex. São Paulo: Novatec, 2007.

MALHOTRA, Naresh K. et al. Introdução à pesquisa de marketing: uma orientação aplicada. 3. ed. Porto Alegre: Bookman, 2005.

MANSUR, Ricardo. Governança de TI: metodologia, frameworks e melhores práticas - Rio de Janeiro: Brasport, 2007.

Governança de TI verde: o ouro verde da nova TI. Rio de Janeiro: Ciência Moderna, 2011.

MARQUIS, H. Uma receita para ITIL. Revista itSM Solutions® DITYTM 2006.

Disponível em: <http:/ /www.itsmsolutions.com/newsletters/DITYvol2iss11.htm> Acesso em: 18 set. 2016.

MATTAR, Fauze Najib. Pesquisa de marketing: metodologia, planejamento. São Paulo: Atlas, 2005.

MOLINARO, Luís Fernando Ramos. Gestão de tecnologia da informação:

governança de TI: arquitetura e alinhamento entre sistemas de informação e negócio / Luís Fernando Ramos Molinaro, Karoll Haussler Carneiro. Rio de Janeiro: LTC, 2011.

OLIVEIRA, Djalma de Pinho Rebouças de. Governança corporativa na prática: integrando acionistas, conselho de administração e diretoria executiva na geração de resultados. São Paulo: Atlas, 2006.

ROESCH, Sylvia Maria Azevedo. Projetos de estágio e de pesquisa em administração: guia para estágios, trabalhos de conclusão, dissertações e estudos de caso. 3. ed. São Paulo: Atlas, 2013.

SILVA, Lucinaldo Cirino da. Avaliação da maturidade ITIL: uma abordagem prática. Brasília: SENAC DF, 2012. 97 f. Disponível em: <http:/ / www.edilms.eti.br/uploads / file/orientacoes/GTIDF03\%20-\%20Lucinaldo\%20Cirino.pdf>. Acesso em: 02 set. 2016. 
SILVEIRA, Alexandre Di Miceli da. Governança corporativa no Brasil e no mundo: teoria e prática. 2. ed. Rio de Janeiro: Elsevier, 2015.

TURBAN, Efraim; VOLONINO Linda. Tecnologia da informação para a gestão [recurso eletrônico]: em busca do melhor desempenho estratégico e operacional; tradução: Aline Evers; revisão técnica: Ângela Freitag Brodbeck. 8. Ed. Dados eletrônicos. Porto Alegre: Bookman, 2013.

VERGARA, Sylvia Constant. Projetos e relatórios de pesquisa em Administração. São Paulo: Atlas, 2000. 